\title{
Hospitalization burden and comorbidities of patients with rheumatoid arthritis in Spain during the period 2002-2017
}

\author{
Mario Gil-Conesa ${ }^{1,2}$, Juan Antonio Del-Moral-Luque ${ }^{1,2}$, Gil-Prieto Ruth², Ángel Gil-de-Miguel², \\ Ramón Mazzuccheli-Esteban ${ }^{3}$ and Gil Rodríguez-Caravaca ${ }^{1,2^{*}}$
}

\begin{abstract}
Background: Rheumatoid arthritis (RA) is a chronic autoimmune rheumatic disease that is associated with multiple comorbidities and has a significant economic impact on the Spanish health system. The objective of this study was to estimate the rates of hospitalization of rheumatoid arthritis in Spain, and describing hospitalization rates and their changing by age, region, RA variant, and when RA as a main cause of hospitalization or a comorbidity.

Methods: Observational descriptive study that reviewed hospital records from the CMBD. We included all hospitalizations of patients in Spain whose main diagnosis or comorbidity in the ICD-9-CM was rheumatoid arthritis during the period of 2002-2017.

Results: A total of 315,190 hospitalizations with the RA code were recorded; $67.3 \%$ were in women. The mean age of the patients was $68.5 \pm 13.9$ years. The median length of hospital stay was 7 days (IQR 3-11 days). In 29,809 of the admissions, RA was coded as the main diagnosis (9.4\%). When RA was not coded as the main diagnosis, the most frequent main diagnoses were diseases of the circulatory system (18.9\%) and diseases of the respiratory system (17.4\%). The hospitalization rate during the period of 2002-2017 was 43.8 (95\% Cl: 43.7-44.0) per 100,000 inhabitants and constantly increased during the period. The total cost for the healthcare system was 1.476 million euros, with a median of 3542 euros per hospitalization (IQR 2646-5222 euros).
\end{abstract}

Conclusions: In Spain, the hospitalization rate of patients with RA increased during the study period, despite the decrease in the hospitalization rate when RA was the main diagnosis.

Keywords: Rheumatoid arthritis, CMBD, Hospital burden, Health system, Epidemiological study, Spain

\section{Background}

Rheumatoid arthritis (RA) is a chronic inflammatory disease that preferentially affects the joints symmetrically; however, it can also damage internal organs and thus should be considered a systemic disease. Systemic involvement and comorbidities can reduce life expectancy [1].

\footnotetext{
* Correspondence: grodriguez@fhalcorcon.es

'Preventive Medicine Unit, Alcorcon Foundation University Hospital, Alcorcón, Madrid, Spain

${ }^{2}$ Preventive Medicine Department, King Juan Carlos University, Alcorcon, Madrid, Spain

Full list of author information is available at the end of the article
}

RA is associated with multiple comorbidities and psychosocial problems, which include cardiovascular diseases, interstitial lung disease, osteoporosis, infections, fatigue and depression [2,3] and an increased risk of early mortality $[4,5]$, amongst others. RA is also associated with an increased incidence of lymphomas, leukaemia and lung cancer [6]. These comorbidities are associated with a significant increase in mortality, disability and costs, which is why they are a priority addressed by the new strategies of the World Health Organization (WHO) [7].

(c) The Author(s). 2020 Open Access This article is licensed under a Creative Commons Attribution 4.0 International License, which permits use, sharing, adaptation, distribution and reproduction in any medium or format, as long as you give appropriate credit to the original author(s) and the source, provide a link to the Creative Commons licence, and indicate if changes were made. The images or other third party material in this article are included in the article's Creative Commons licence, unless indicated otherwise in a credit line to the material. If material is not included in the article's Creative Commons licence and your intended use is not permitted by statutory regulation or exceeds the permitted use, you will need to obtain permission directly from the copyright holder. To view a copy of this licence, visit http://creativecommons.org/licenses/by/4.0/ The Creative Commons Public Domain Dedication waiver (http://creativecommons.org/publicdomain/zero/1.0/) applies to the data made available in this article, unless otherwise stated in a credit line to the data. 
The worldwide prevalence of RA is estimated to be $0.24 \%$, whereas the prevalence of this disease is $0.66 \%$ in Northern Europe [8] and $0.44 \%$ in Western Europe [9]. In Spain, the prevalence of RA is $0.5 \%$ ( $0.8 \%$ in women and $0.2 \%$ in men), with approximately 200,000 cases and a 4:1 ratio between women and men, according to the EPISER study (National Survey on the Prevalence of Rheumatic Diseases in Spain) [10]. The incidence of RA in our country is 8.3 cases/100,000 inhabitants, which increases with age in both sexes [11]. According to the National Health Survey (ENSE 2011/2012), in the section "Chronic Problems of the Adult Population", under the label of "Arthrosis, Arthritis and Rheumatism", RA was classified as the primary disease in women (affecting 25.1\%) and as the third most common disease in men (affecting 11.1\%) [12].

In Spain, $74 \%$ of the total RA costs correspond to direct costs, and 26\% correspond to indirect costs [13].

There is clearly a lack of recent studies describing the trend in rheumatoid arthritis hospitalizations in Spain, its costs and differences by age and sex, as well as its variants.

This study provides relevant information to understand the distribution of this disease in Spain, and that has been carried out with reliable and complete national data representative of the population of our country. In addition, hospitalization rates for this disease have not been presented in recent studies, making it necessary to describe the changes in its trends, as well as its cost to the health system.

We consider that it is necessary to make large sample studies in which we can consistently observe differences that can help us clarify the etiology of this complex disease.

Our study aimed to estimate the rates of hospitalization of rheumatoid arthritis in Spain during the period 20022017 and describing hospitalization rates by year, age, region, RA variant, and when RA as a main cause of hospitalization or a comorbidity. As secondary objectives, we also described main diagnosis when RA was not the cause of hospitalization, and its principal comorbidities when it was the main cause, describing as well the costs of RA as a global and individually.

\section{Methods}

\section{Study design}

An observational descriptive study was performed using data from the Minimum Basic Data Set (CMBD) of the Ministry of Health, Social Services and Equality of Spain. The CMBD is a compulsory registry for both public and private hospitals that provides statistical knowledge of hospital morbidity. This information helps in the planning and evaluation of health systems [14, 15] and includes an estimated $98 \%$ of hospital admissions, covering
99.5\% of the Spanish population [16]. We worked with episodes of hospitalization. All patients were identified by their main diagnosis code and their medical record number, excluding second episodes for individual analysis but including them in the total number of episodes studied.

The main inclusion criterion in the study was the diagnosis of RA at hospital discharge (code 714.0 or its variants) and all the patients with RA admitted to the hospital were captured by the coding system.

\section{Sampling and variables}

Our registry included 315,190 hospital admissions from a period of 16 years (from January 1, 2002 to December $31,2017)$. A total of 69 variables were collected; from these, this study analysed sex, age, year, average stay, cost of hospitalization, autonomous community of admission, primary diagnosis and secondary diagnoses (up to 13 diagnoses). The main diagnostic variable was considered the reason for hospitalization, and the rest of the diagnostic variables were assessed as comorbidities. The cost of each episode of RA and its variants was calculated by the Ministry of Health and it is included in the CMBD database and it corresponds to the estimated average cost for each Group Related to the Diagnosis (DRG) updated for the year of reference. The calculated cost took into account each severity level of the episode.

RA and its variants were coded in one or more of 14 diagnostic variables based on the Ninth Edition of the International Classification of Diseases (ICD-9-CM). According to this classification, RA and all its variants were registered with the code 714 followed by one or two figures.

The patients were grouped into the following age ranges: under 20 years old, 20-29 years old, 30-39 years old, 40-49 years old, 50-59 years old, 60-69 years old, 70-79 years old, 80-89 years old and over 89 years old. To calculate the hospitalization rates (by year, age and autonomous community), the number of hospitalizations of RA patients was used as the numerator and the official population figure of the National Institute of Statistics [17] was used as the denominator, calculated per 100,000 inhabitants.

\section{Statistical analysis}

Qualitative variables were described with their frequency distribution and were compared using Pearson's Chisquare test or Fisher's exact test if their application criteria were not met. Quantitative variables were described with the mean and standard deviation (SD) or the median and interquartile range (IQR) if they did not follow normal distributions and were compared using Student's t-test when the data followed a normal distribution or with the Mann-Whitney U test otherwise. Quantitative 
variables with more than two categories were compared using analysis of variance (ANOVA), and when the application conditions were not met, the non-parametric Kruskal-Wallis test was used. The statistical analysis was performed using the statistical program SPSS 22.0 (SPSS Inc., Chicago, IL). Statistically significant differences were those with $p<0.05$; all estimates were described with their 95\% confidence intervals. Patient information was anonymized before performing the analysis.

\section{Results}

A total of 315,190 hospitalizations were recorded for RA patients, both in primary and secondary diagnosis, during the period of 2002-2017. Of these admissions, 211, 967 were women (67.3\%), and 103,199 were men (32.7\%). The mean age of the patients was $68.5 \pm 13.9$ years, corresponding to $68.2 \pm 14.5$ years in women and $69.1 \pm 12.6$ years in men $(p>0.05)$. The median length of hospital stay over the entire study period was 7 days (IQR 3-11 days); the length of stay was significantly higher in 2002 (8 days, IQR 4-13 days) compared to 2017 ( 6 days, IQR $3-10$ days) $(p<0.05)$. In 2002, the cost of hospitalization for RA patients was 38 million euros, with a median hospitalization cost per admission of 2314 euros (IQR 2032-3417 euros), whereas the total cost was 142 million euros in 2017, with a median hospitalization cost per admission of 4396 euros (IQR 3384-5945 euros) $(p<0.05)$. The overall cost of hospitalizations for patients with RA in the Spanish Health System was 1.476 million euros during the period of 20022017, with a median hospitalization cost per admission of 3542 euros (IQR 2646-5222 euros).

\section{Hospitalization rates by sex, age, year and diagnosis}

The hospitalization rate in Spain for RA during the period of 2002-2017 was 43.8 (95\% CI: 43.7-44.0) hospitalizations per 100,000 population-years. By sex, the rate of hospitalization was 58.1 (95\% CI: $58.0-58.3$ ) per 100,000 population-years in women and 29.1 (95\% CI: $29.0-29.3)$ in men $(p<0.05)$. When stratified by age, the lowest hospitalization rate corresponded to those under 20 years old: 0.53 (95\% CI: $0.49-0.56$ ) per 100,000 population-years, and the highest corresponded to those between 80 and 90 years old: 219.0 per 100,000 population-years (95\% CI: 217.5-220.6) (Table 1). When comparing the annual rate of hospitalization without differentiating whether RA was coded as the main diagnosis or a comorbidity, there was an annual increase in this rate from 31.6 per 100,000 inhabitants in 2002 to 56.3 per 100,000 inhabitants in $2017(p<0.05)$ (Fig. 1).

The overall hospitalization rates during the study period were 4.1 (95\% CI: 4.0-4.2) per 100,000 inhabitants when RA was coded as the main diagnosis and 39.7 (95\% CI: 39.6-39.8) when it was a comorbidity at
Table 1 Hospitalization rates for rheumatoid arthritis in Spain (2002-2017) by age. Hospitalization rate per 100,000 inhabitants

\begin{tabular}{lll}
\hline Age & Rate & $95 \% \mathrm{Cl}$ \\
\hline$<20$ years & 0.53 & $0.49-0.56$ \\
$20-29$ years & 2.93 & $2.83-3.04$ \\
$30-39$ years & 7.93 & $7.78-8.08$ \\
$40-49$ years & 17.98 & $17.76-18.21$ \\
$50-59$ years & 45.95 & $45.62-46.28$ \\
$60-69$ years & 101.24 & $100.50-102.04$ \\
$70-79$ years & 183.29 & $182.31-184.36$ \\
$80-89$ years & 219.08 & $217.59-220.62$ \\
$>89$ years & 136.58 & $133.73-139.65$ \\
Total & 43.88 & $43.77-44.00$ \\
\hline
\end{tabular}

admission. The highest annual hospitalization rate for RA as the main diagnosis was 8.1 (95\% CI: 7.9-8.2) per 100,000 inhabitants in 2003, whereas the lowest was 1.9 (95\% CI: 1.8-2.0) in 2017; overall, there was a declining trend since 2003. Conversely, the data displayed an increasing trend of annual hospitalization rates when RA was a comorbidity; the lowest rate was in 2002: 24.5 (95\% CI: 24.1-24.9) per 100,000 inhabitants, whereas the highest was in 2017: 54.5 (95\% CI: 54.0-54.9) per 100, 000 inhabitants (Table 2).

\section{Rheumatoid arthritis as the main diagnosis or comorbidity on admission}

When RA was the main diagnosis, a total of 29,809 hospitalizations were recorded during the study period, with a hospitalization rate of 4.1 (95\% CI: 3.9-4.3) per 100 , 000 population-years. The mean age of the patients admitted was $60.4 \pm 14.7$ years, and $71.6 \%$ of the patients were women. The average hospital stay was $7.1 \pm 8.3$ days, and the average cost per hospitalization was $3503 \pm 2224$ euros. RA (code 714.0) was classified as the main diagnosis in $9.2 \%$ of cases, followed by rheumatic lung and non-specific inflammatory polyarthropathy in 0.1 and $0.03 \%$ of cases, respectively. The rest of the variants of RA were classified as the main diagnosis in less than $0.03 \%$ of cases (Table 3). Amongst the 285,381 hospitalizations of patients with RA as a comorbidity, the most frequent causes of admission were diseases of the circulatory system $(n=54,123,18.9 \%)$, diseases of the respiratory system $(n=49.876,17.4 \%)$ and diseases of the osteomyoarticular system and connective tissue $(n=$ 32.003, 11.2\%) (Table 4).

\section{Regional rates of hospitalization for rheumatoid arthritis in Spain}

In Spain, the highest rates of hospitalization for RA per 100,000 population-years by autonomous communities 


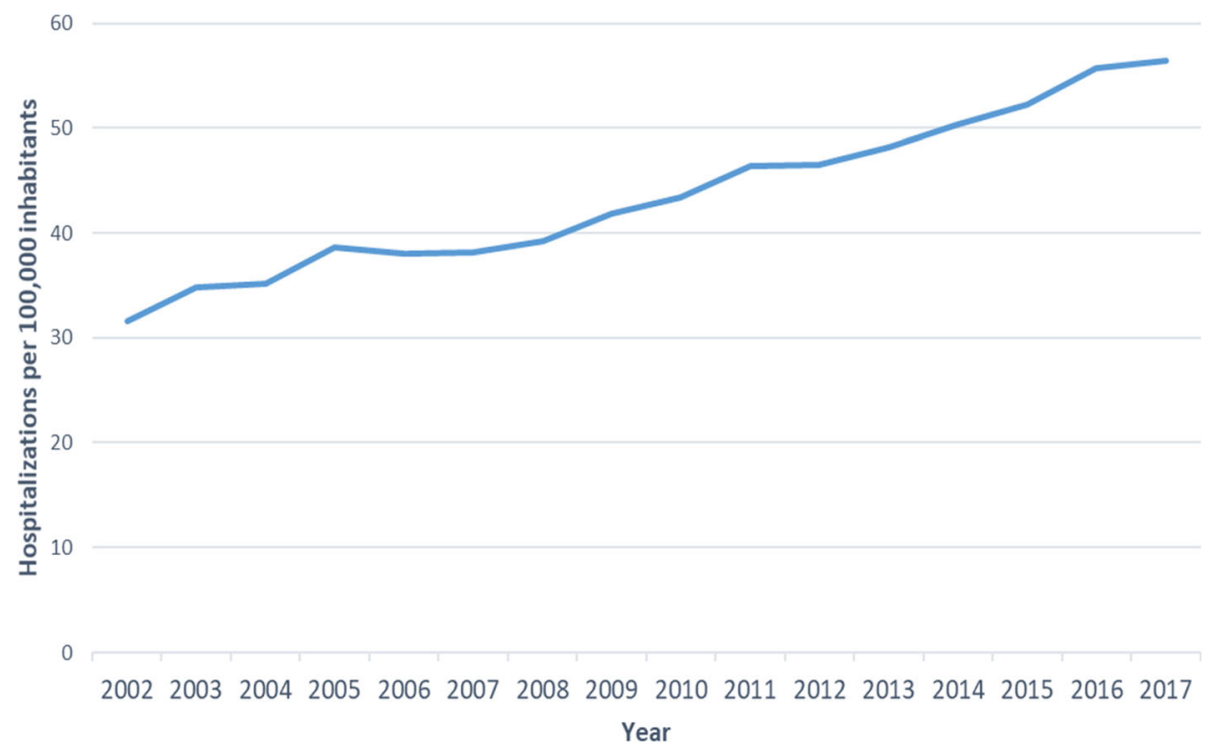

Fig. 1 Annual hospitalization rates for rheumatoid arthritis in Spain (2002-2017)

(as the main diagnosis or comorbidity) were found in Castilla y León (69.9), Cantabria (69.9), Asturias (62.1) and Extremadura (55.8). By contrast, the lowest rates were found in Melilla (16.7), Ceuta (17.1), Canary Islands (27.9) and Balearic Islands (30.1) (Fig. 2).

Table 2 Annual hospitalization rates in Spain (2002-2017) for rheumatoid arthritis as the main diagnosis or comorbidity. Annual hospitalization rates per 100,000 inhabitants ${ }^{a}$

\begin{tabular}{llllll}
\hline Year & \multicolumn{2}{l}{ RA as main diagnosis } & & \multicolumn{2}{l}{ RA as comorbidity } \\
\cline { 2 - 3 } & Rate & $95 \% \mathrm{Cl}$ & & Rate & $95 \% \mathrm{Cl}$ \\
\hline 2002 & 7.11 & $6.97-7.25$ & & 24.50 & $24.08-24.92$ \\
2003 & 8.10 & $7.98-8.22$ & & 26.67 & $26.25-27.10$ \\
2004 & 7.42 & $7.28-7.55$ & & 27.79 & $27.36-28.22$ \\
2005 & 7.10 & $6.97-7.24$ & & 31.57 & $31.13-32.02$ \\
2006 & 5.70 & $5.55-5.85$ & & 32.37 & $31.93-32.82$ \\
2007 & 4.28 & $4.14-4.43$ & & 33.90 & $33.46-34.34$ \\
2008 & 4.23 & $4.08-4.37$ & & 35.00 & $34.56-35.44$ \\
2009 & 3.82 & $3.69-3.96$ & & 37.99 & $37.54-38.44$ \\
2010 & 3.38 & $3.25-3.52$ & & 39.99 & $39.55-40.44$ \\
2011 & 3.34 & $3.20-3.47$ & & 43.08 & $42.63-43.53$ \\
2012 & 2.78 & $2.64-2.90$ & & 43.71 & $43.26-44.15$ \\
2013 & 2.56 & $2.44-2.68$ & & 45.66 & $45.21-46.11$ \\
2014 & 2.18 & $2.06-2.30$ & & 48.21 & $47.76-48.66$ \\
2015 & 2.09 & $1.98-2.21$ & & 50.12 & $49.67-50.57$ \\
2016 & 2.03 & $1.91-2.15$ & 53.74 & $53.29-54.19$ \\
2017 & 1.93 & $1.82-2.05$ & 54.45 & $54.00-54.91$ \\
Total & 4.15 & $4.11-4.19$ & 39.73 & $39.62-39.84$ \\
\hline
\end{tabular}

${ }^{\mathrm{a}} R A$ rheumatoid arthritis

\section{Discussion}

The study carried out by the EPISER research group [18] established a population sample studied through surveys, however, our study has objective data from hospitals throughout the country, so we consider it a necessary update of the costs that this disease entails, as well as the hospitalization data of rheumatoid arthritis in the 16 years studied.

Table 3 ICD-9-CM codes of rheumatoid arthritis and its variants when rheumatoid arthritis was coded as the main diagnosis ${ }^{a}$

\begin{tabular}{llll}
\hline Type of rheumatoid arthritis & Code & \multicolumn{2}{l}{ Principal diagnostic } \\
\cline { 3 - 4 } & & $\mathrm{N}$ & $\%$ \\
\hline Rheumatoid arthritis & 714.0 & 29,059 & $9.22 \%$ \\
Felty syndrome & 714.1 & 37 & $0.01 \%$ \\
RA with visceral or systemic implication & 714.2 & 40 & $0.01 \%$ \\
RA youth polyarticular chronicle & 714.30 & 78 & $0.02 \%$ \\
Acute youth polyarticular RA & 714.31 & 19 & $0.01 \%$ \\
Oligoarticular or pauciarticular juvenile RA & 714.32 & 11 & $0.003 \%$ \\
Monoarticular youth RA & 714.33 & 12 & $0.004 \%$ \\
Postrheumatic arthropathy chronicle & 714.4 & 19 & $0.01 \%$ \\
Rheumatic lung & 714.81 & 412 & $0.13 \%$ \\
Other inflammatory polyartopathies & 714.89 & 39 & $0.01 \%$ \\
Inflammatory non-specific polyartropathy & 714.9 & 83 & $0.03 \%$ \\
Total RA & & 29,809 & $9.46 \%$ \\
Other pathologies & & 285,381 & $90.54 \%$ \\
Total & & 315,190 & $100 \%$ \\
\hline
\end{tabular}

${ }^{\mathrm{a}} R A$ rheumatoid arthritis 
Table 4 Causes of hospitalization when rheumatoid arthritis was not coded as the main diagnosis

\begin{tabular}{|c|c|c|}
\hline ICD-9-MC codes & $\mathrm{N}$ & $\%$ \\
\hline 1. Infectious and parasitic diseases (001-139) & 7447 & $2.61 \%$ \\
\hline 2. Neoplasms (140-239) & 20,514 & $7.19 \%$ \\
\hline 3. Endocrine, metabolic, and nutritional diseases and immune disorders (240-279) & 5500 & $1.93 \%$ \\
\hline 4. Diseases of the blood and haematopoietic organs (280-289) & 5434 & $1.90 \%$ \\
\hline 5. Mental, behavioural and neurodevelopmental disorders (290-319) & 2429 & $0.85 \%$ \\
\hline 6. Diseases of the nervous system and the sense organs (320-389) & 6726 & $2.36 \%$ \\
\hline 7. Diseases of the circulatory system (390-459) & 54,123 & $18.97 \%$ \\
\hline 8. Diseases of the respiratory system (460-519) & 49,876 & $17.48 \%$ \\
\hline 9. Diseases of the digestive system (520-579) & 31,864 & $11.17 \%$ \\
\hline 10. Diseases of the genitourinary system (580-629) & 15,675 & $5.49 \%$ \\
\hline 11. Complications of pregnancy, childbirth and puerperium (630-679) & 3466 & $1.21 \%$ \\
\hline 12. Diseases of the skin and subcutaneous tissue (680-709) & 4915 & $1.72 \%$ \\
\hline 13. Diseases of the osteomyoarticular system and connective tissue (710-739) & 32,003 & $11.21 \%$ \\
\hline 14. Congenital anomalies (740-759) & 383 & $0.13 \%$ \\
\hline 15. Signs, symptoms and ill-defined states (780-799) & 12,385 & $4.34 \%$ \\
\hline 16. Injuries and poisoning (800-999) & 27,579 & $9.66 \%$ \\
\hline 17. Factors that influence the state of health and contact with health services (V01-V89) & 4922 & $1.72 \%$ \\
\hline 18. Lost to follow-up (ZZZ.ZP) & 140 & $0.05 \%$ \\
\hline Total & 285,381 & $100 \%$ \\
\hline
\end{tabular}

We have found an increase in the hospitalization rate for this disease during the period studied, and that seems to be in accordance with what has been done by other authors in similar conditions [19].

In our study, the rate of hospitalization for RA in women seems to be much higher than that for men what seems to be in the same direction as observed by other studies [18] [20]; furthermore, the rate of hospitalization increased with age, reflecting a trend that is consistent with the literature $[10,11]$.

The hospital stay has been significantly reduced during the period studied from 8 to 6 days, despite which, the total cost of rheumatoid arthritis has increased. This is due to the increase in hospitalizations for this disease and the new biological medications, which have significantly increased the treatment of this disease [20].

The finding in our study of a decrease in the annual hospitalization rate when RA is coded as the main diagnosis (and therefore considered the cause of hospitalization) could be as well result of the recent widespread use of new therapies with drug modifiers such as disease and biological agents [21]. The increase in the hospitalization rate when RA was coded as a comorbidity could be explained by the increase in the pluripathology and chronicity in patients affected by this disease for years [22].

The main causes of hospitalization in patients with RA were diseases of the circulatory, respiratory, osteomyoarticular and connective tissue systems, which constituted almost $50 \%$ of all admission pathologies. This corroborates what has been published in several studies demonstrating that cardiovascular diseases are one of the main comorbidities that accompany RA [8, 21-23]. In our study, only $2.6 \%$ of RA patient admissions were due to infections; however, in the literature, the recurrence of infections that accompany patients with this disease has been noted [23], particularly opportunistic infections such as herpes zoster or tuberculosis $[24,25]$.

In our study, the association of episodes with gastrointestinal diseases was also frequent, which has been shown to be consistent with other data in the literature and seems to have been increased in relation to the evolution of RA treatment [20,23].

Patients with RA also report a significant worsening of their quality of life when they have two or more associated comorbidities [26].

In Spain, the highest hospitalization rates for RA were registered in the autonomous communities of the centre and north-west of the peninsula. The lowest rates were found in Melilla, Ceuta and both archipelagos (Canary and Balearic Islands) and in the regions located in the Mediterranean climatic zone (with the exception of Navarra).

The literature also indicates that there is a difference in the incidence of RA and its exacerbations between populations within the same country, likely because of 


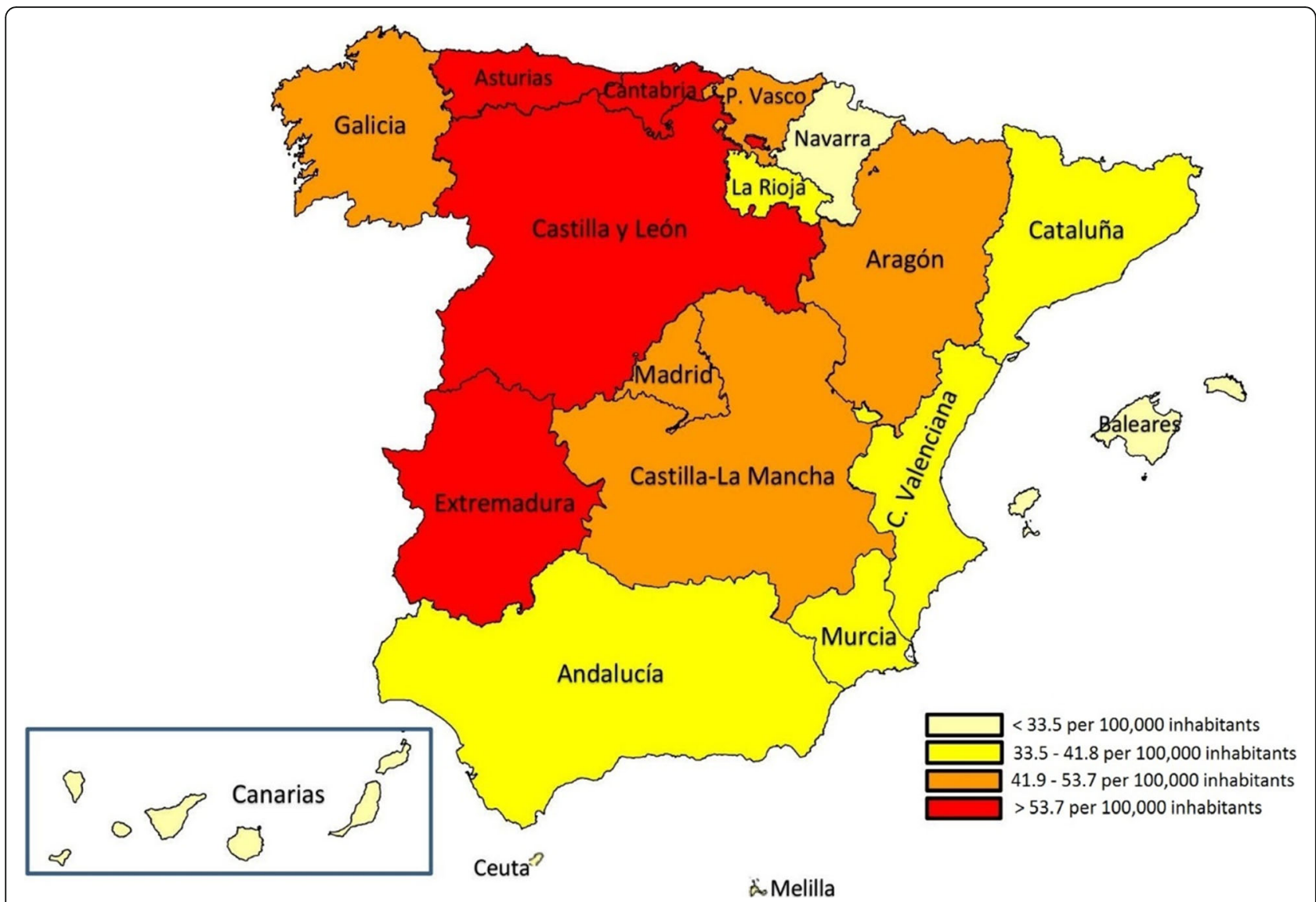

Fig. 2 Hospitalization rates for patients with rheumatoid arthritis, by autonomous community, during the period of 2002-2017. Freely available, depicted by Flourish ${ }^{\circledast}$ public access

variations in climate, environmental exposure, genetic factors and behavioural factors, amongst others [27, 28].

The limitation of this study derives from the use of a secondary information source. To improve the analysis of big data will be a long-term commitment for institutions and health authorities, not without risk or complexity, because they do not yet know all the possibilities that technologies and techniques can offer around the management and large-scale data analysis [29]. The quality of the CMBD depends on the clinical history and its codification, which leads to variability between hospital centres. However, since 2001, quality control measures have been developed to assess the internal validity of the database and improve it [30]. We have added information from other previous studies on disease burden that we have taken into account in our conclusions [31] A strength of our work is filling knowledge gaps in the field of rheumatological diseases especially hospitalization rates and their differences by age, sex and region, as well as their evolution and cost to our healthcare system. Therefore, we consider this study to be novel and of great interest.

\section{Conclusion}

The epidemiology reported in our work follows the line of other international studies on RA and its variants. The rate of hospitalization of patients with RA increased during the period of 2002-2017 despite the decrease in the rate of RA as the main diagnosis and the use of biological therapies and more aggressive strategies to control the disease. The observed increase in hospitalization and the cost of this disease, shows that studies of incidence of the disease of larger size should be carried out to help establish the risk factors and associated health costs.

Therefore, this work is open to future lines of research through the exploitation of the CMBD and other databases that allow us to collect more information on RA to evaluate, manage and plan the processes related to this pathology in our environment.

\section{Abbreviations}

CMBD: Minimum Basic Data Set; Cl: Confidence intervals; RA: Rheumatoid arthritis

\section{Acknowledgments}

We thank Mr. Sergio Rodríguez Villar for his contribution to the registration and management of the data and for his support with the administrative tasks. 


\section{Authors' contributions}

MGC participated in the study design, carried out the study, made all the changes and followed-up the revision, revised it critically for important intellectual content and carried out the last changes. JADML designed the study, carried out the study, performed the statistical analysis and drafted the manuscript. RGP participated in the study design and drafted the manuscript. AGM participated in the study design and drafted the manuscript. RME participated in the study design and revised it critically for important intellectual content. GRC participated in the study design, revised it critically for important intellectual content and drafted the manuscript. All authors read and approved the final version.

\section{Author's information}

The authors are members of a multidisciplinary team made up of specialists on public health, preventive medicine, rheumatology and teaching. They work at Alcorcon Foundation University Hospital and King Juan Carlos University in Madrid. All of them are MD and professors at Rey Juan Carlos University and MGC, JADM, AGM and GRC are MPH. RGP, AGM, RME and GRC are PhD.

\section{Funding}

This study was carried out without any funding.

\section{Availability of data and materials}

Public access to the database is closed. The data sets used and/or analysed during the current study are available from the corresponding author on reasonable request.

\section{Ethics approval and consent to participate}

No ethical approval was needed for this study because it was based on secondary analysis of the data obtained from the CMBD (Minimum Basic Data Set) of the Ministry of Health, Social Services and Equality of Spain. The data were completely anonymous and this study uses data with no identifiable information on the survey participants. The Ministry of Health, Social Services and Equality of Spain (Subdirección General del Instituto de Información) gave us administrative permission to access and use the data on which this study is based.

\section{Consent for publication}

Not applicable.

\section{Competing interests}

The authors declare that they do not have competing interests.

\section{Author details}

'Preventive Medicine Unit, Alcorcon Foundation University Hospital, Alcorcón, Madrid, Spain. ${ }^{2}$ Preventive Medicine Department, King Juan Carlos University, Alcorcon, Madrid, Spain. ${ }^{3}$ Rheumatology Unit, Alcorcon Foundation University Hospital, Alcorcón, Madrid, Spain.

Received: 12 August 2019 Accepted: 21 April 2020

Published online: 04 May 2020

\section{References}

1. Tornero J, Sanmartí R, Rodríguez V, Martín E, Marenco JL, González I, et al. Update of the consensus statement of the Spanish Society of Rheumatology on the management of biologic therapies in rheumatoid arthritis. Reumatol Clin. 2010:6:23-36.

2. Cutolo M, Kitas GD, Van Riel PL. Burden of disease in treated rheumatoid arthritis patients: going beyond the joint. Semin Arthritis Rheum. 2014;43: 479-88

3. Marrie RA, Hitchon CA, Walld R, Patten SB, Bolton JM, Sareen J, et al. Increased burden of psychiatric disorders in rheumatoid arthritis. Arthritis Care Res (Hoboken). 2018;70:970-8.

4. Nordgren B, Fridén C, Demmelmaier I, Bergström G, Opava CH. Long-term health-enhancing physical activity in rheumatoid arthritis-the PARA 2010 study. BMC Public Health. 2012;12:397.

5. England BR, Sayles H, Michaud K, Caplan L, Davis LA, Cannon GW, et al. Cause-specific mortality in male US veterans with rheumatoid arthritis. Arthritis Care Res (Hoboken). 2016;68:36-45.
6. Abásolo L, Júdez E, Descalzo MA, González I, Jover JA, Carmona L, et al. Cancer in rheumatoid arthritis: occurrence, mortality, and associated factors in a south European population. Semin Arthritis Rheum. 2008;37:388-97.

7. World Health Organization. Global Action Plan for the prevention and control of noncommunicable diseases 2013-2020. [cited 2019 Feb 10]. Available from: http://www.who.int/nmh/events/ncd_action_plan/en/.

8. Van Vilsteren $M$, Boot $C R$, Steenbeek R, Van Schaardenburg D, Voskuy AE, Anema JR. An intervention program with the aim to improve and maintain work productivity for workers with rheumatoid arthritis: design of a randomized controlled trial and cost-effectiveness study. BMC Public Health. 2012;12:496

9. Cross M, Smith E, Hoy D, Carmona L, Wolfe F, Vos T, et al. The global burden of rheumatoid arthritis: estimates from the global burden of disease 2010 study. Ann Rheum Dis. 2014;73:1316-22.

10. Carmona L, Villaverde V, Hernández-García C, Ballina J, Gabriel R, Laffon A, et al. The prevalence of rheumatoid arthritis in the general population of Spain. Rheumatology (Oxford). 2002;41:88-95.

11. Carbonell J, Cobo T, Balsa A, Descalzo MA, Carmona L, SERAP Study Group. The incidence of rheumatoid arthritis in Spain: results from a nationwide primary care registry. Rheumatology (Oxford). 2008;47:1088-92.

12. Ministerio de Sanidad Servicios Sociales e Igualdad. Encuesta Nacional De Salud: ENSE 2011-2012; 2013. p. 48

13. Ruiz MD, Hernández B, Ariza R, Carmona L, Ballina J, Navarro F. Análisis de costes en una cohorte de enfermos con artritis reumatoide atendidos en área especializada de reumatología en España. Reumatol Clin. 2005;1:193-9.

14. Jiménez A, García J, Lara A. Information systems for clinicians I. how to know what type of patients are attended in our hospitals. Rev Clin Esp. 2010;210:298-303

15. Gil-Prieto R, Pascual-Garcia R, San-Roman-Montero J, Martinez-Martin P, Castrodeza-Sanz J, Gil-de-Miguel A. Measuring the burden of hospitalization in patients with Parkinson's disease in Spain. PLos One. 2016;11(3):e0151563.

16. Análisis y desarrollo de los GDR en el Sistema Nacional de Salud. [cited 2019 Apr 12]. Available from: http://www.msssi.gob.es/estadEstudios/ estadisticas/docs/analisis.pdf.

17. Instituto Nacional de Estadística. [cited 2019 May 1]. Available from: http:// www.ine.es/jaxi/Tabla.htm?path=/t20/e245/p08/10/\&file=02002.px.

18. Carmona L, Ballina J, Gabriel R, Laffon A. The burden of musculoskeletal diseases in the general population of Spain: results from a national survey. Ann Rheum Dis. 2001;60:1040-5.

19. Moradi-Lakeh M, Forouzanfar MH, Emil Vollset S, El Bcheraoui C, Daoud F, Afshin A, Raghid C, Khalil I, Higashi H, Magdy M, El Razek A, Ahmad Kiadaliri A, Khurshid A, Akseer N, et al. Burden of musculoskeletal disorders in the eastern Mediterranean region, 1990-2013: findings from the global burden of disease study 2013. Ann Rheum Dis. 2017;76:1365-73.

20. Andrade P, Sacristán JA, Rentero ML, Hammen V, Dilla T. The burden of rheumatoid arthritis in Spain. Health Econ Outcome Res Open Access. 2017; 3:126

21. Singh JA, Furst DE, Bharat A, Curtis JR, Kavanaugh AF, Kremer JM, et al. 2012 update of the 2008 American College of Rheumatology recommendations for the use of disease-modifying antirheumatic drugs and biologic agents in the treatment of rheumatoid arthritis. Arthritis Care Res (Hoboken). 2012;64: $625-39$.

22. Román P. Ruiz-Cantero A. Polypathology, an emerging phenomenon and a challenge for healthcare systems. Rev Clin Esp. 2017;217:229-37.

23. Uhlig T, Moe RH, Kvien TK. The Burden of Disease in Rheumatoid Arthritis. Pharmacoeconomics. 2014;32:841-51. https://doi.org/10.1007/s40273-014-0174-6.

24. Carmona L, Cross M, Williams B, Lassere M, March L. Rheumatoid arthritis. Best Pract Res Clin Rheumatol. 2010;24:733-45.

25. Listing J, Gerhold K, Zink A. The risk of infections associated with rheumatoid arthritis, with its comorbidity and treatment. Rheumatol. 2013; 52:53-61.

26. Villaverde V, Loza E, Ortiz A, Martinez-Lopez JA, Toledano E, Lajas C, et al. A systematic literature review of the impact of comorbidity on quality of life and costs in patients with rheumatoid arthritis. The Gecoar Study. Ann Rheum Dis. 2014;73:418

27. Roux CH, Saraux A, Le Bihan E, Fardellone P, Guggenbuhl P, Fautrel B, et al. Rheumatoid arthritis and spondyloarthropathies: geographical variations in prevalence in France. J Rheumatol. 2007:34:117-22.

28. Costenbader KH, Chang SC, Laden F, Puett R, Karlson EW. Geographic variation in rheumatoid arthritis incidence among women in the United States. Arch Intern Med. 2008;168:1664-70. 
29. Ehrenstein V, Nielsen H, Pedersen AB, Johnsen SP, Pedersen L. Clinical epidemiology in the era of big data: new opportunities, familiar challenges. Clin Epidemiol. 2017;9:245-50.

30. Rodríguez MM, Perea-Milla E, Librero J, Buzón ML, Rivas F. Análisis del control de calidad del Conjunto Mínimo de Datos Básicos de Andalucía de los años 2000 a 2003. Grupo VPM-IRYSS.

31. Haro JM, Tyrovolas S, Garin N, Diaz-Torne C, Carmona L, Sanchez-Riera L, Perez-Ruiz F, Christopher JL, Murray CJ. The burden of disease in Spain: results from the global burden of disease study 2010. BMC Med. 2014;12:236

\section{Publisher's Note}

Springer Nature remains neutral with regard to jurisdictional claims in published maps and institutional affiliations.

Ready to submit your research? Choose BMC and benefit from:

- fast, convenient online submission

- thorough peer review by experienced researchers in your field

- rapid publication on acceptance

- support for research data, including large and complex data types

- gold Open Access which fosters wider collaboration and increased citations

- maximum visibility for your research: over $100 \mathrm{M}$ website views per year

At $\mathrm{BMC}$, research is always in progress.

Learn more biomedcentral.com/submissions 